\title{
TRILOBITE VISION: A COMPARISON OF SCHIZOCHROAL AND HOLOCHROAL EYES WITH THE COMPOUND EYES OF MODERN ARTHROPODS.
}

FORDYCE, David. Department of Biological Sciences, University of Maryland Baltimore County, Baltimore, MD 21228; CRONIN, Thomas W. Department of Biological Sciences, University of Maryland Baltimore County, Baltimore, MD 21228

The compound eyes of trilobites provide the best examples of fossilized sensory organs for which the function in life can be worked out today, because the optical array of their corneal lenses preserves the geometry with which the eye originally sampled the visual world. An analysis of trilobite vision is strengthened by the use of new mathematical approaches to compound eye design. In particular, the product of the facet diameter (D) and the interommatidial angle $(\Delta \phi)$ gives the value of the eye parameter, $\mathrm{D} \Delta \phi$, which is a reliable indicator of the photic conditions in which the eye was used. In modern arthropods, $\mathrm{D} \Delta \phi$ values range from 0.3 for animals active in bright sunlight to 20 or more for nocturnal or deep-sea animals.

Three types of compound eyes existed in trilobites: schizochroal, holochroal, and abathochroal. We examined the schizochroal and holochroal types.

Schizochroal eyes were studied in the phacopid species Phacops rana crassituberculata and Phacops rana milleri. We measured the diameter of every corneal lens, and estimated its optical axis by taking the normal to the plane of the lens's diameter. In both species, each eye covered almost exactly $180^{\circ}$ of visual space in azimuth with no binocular overlap, from directly anterior to directly posterior. Vertically, the visual field extended from the horizon to about $40^{\circ}$ in elevation. Facet diameters and interommatidial angles were large, giving eye parameter values ranging from 10 to $>150$. These are much greater than in any living arthropod, implying that modern compound eye theory does not apply to schizochroal eyes. We believe that each ommatidium of the schizochroal eye served as a miniature lens eye. If so, phacopid vision must have been unique, with multiply overlapping visual fields. Such a design would have required considerable central processing, but could have provided exceptional opportunities for spatial, spectral, and polarizational analysis.

We examined holochroal compound eyes in Asaphus cornutus and Isotelus "gigas". Here, visual field coverage was greater than in the schizochroal eye type, with a small amount of frontal binocular overlap. Holochroal eyes contain far more ommatidia than do schizochroal types, reducing both facet diameter (D) and interommatidial angle $(\Delta \phi)$. Thus, $\mathrm{D} \Delta \phi$ values in these species fall into the same range as in modern compound eyes. This implies that function of the holochroal eye was similar to that of modern crustaceans and insects.

This material is based on research supported by the National Science Foundation under Grants No. BNS-8518769 and BNS-8917183. 